\title{
Analysis and Implementation of a DC-DC Converter with an Active Snubber
}

\author{
Bor-Ren Lin ${ }^{\dagger}$ and Li-An Lin* \\ $\dagger *$ Dept. of Electrical Eng., National Yunlin University of Science and Technology, Yunlin, Taiwan
}

\begin{abstract}
This paper presents a soft switching converter to achieve the functions of zero voltage switching (ZVS) turn-on for the power switches and dc voltage step-up. Two circuit modules are connected in parallel in order to achieve load current sharing and to reduce the size of the transformer core. An active snubber is connected between two transformers in order to absorb the energy stored in the leakage and magnetizing inductances and to limit the voltage stresses across the switches. During the commutation stage of the two complementary switches, the output capacitance of the two switches and the leakage inductance of the transformers are resonant. Thus, the power switches can be turned on under ZVS. No output filter inductor is used in the proposed converter and the voltage stresses of the output diodes is clamped to the output voltage. The circuit configuration, the operation principles and the design considerations are presented. Finally, laboratory experiments with a $340 \mathrm{~W}$ prototype, verifying the effectiveness of the proposed converter, are described.
\end{abstract}

Key Words: DC Converter, Soft Switching

\section{INTRODUCTION}

In order to help mitigate climate changes and environmental pollution, the Environment Protection Agency (EPA) and the Climate Saver Computing Initiative (CSCI) have proposed efficiency requirements for modern power supply units. DCDC [1]-[9] converters with zero voltage switching (ZVS), have been proposed with advantages such as high frequency operation, ZVS or zero current switching (ZCS) switching and high circuit efficiency. However, the voltage stresses or current stresses in the resonant converters are much to high for high input voltage or current applications. Active snubbers [10]-[12] have been presented to reduce voltage spikes and switching losses and to increase circuit efficiency. Power switches are turned on under ZVS during the transition interval based on the transformer leakage inductance and the switch output capacitance. However, a high power rating and a high power density are required in many practical applications such as computer servers and telecommunication power supplies. One way to increase output power is to connect two or more converter cells in parallel. Thus the current stresses and the power losses can be distributed among all of the converter cells. An interleaved PWM controller can control several converter cells with a phase-shifted PWM technique to realize load current sharing and ripple current cancellation. Parallel forward converters with soft switching techniques

Manuscript received Jan. 16, 2011; revised Jul. 8, 2011

Recommended for publication by Associate Editor Tae-Woong Kim.

$\dagger$ Corresponding Author: linbr@yuntech.edu.tw

Tel: +886-5-5517456, Fax: +886-5-5312065, National Yunlin University

* Dept. of Electrical Eng., National Yunlin University of Science and

Technology, Taiwan have been presented in [13]-[15] to realize ZVS operation and to achieve conversion efficiency improvements. However, the control schemes are more difficult to implement and many switches are used in the circuits.

This paper presents a parallel soft switching converter with an output voltage doubler topology. Two circuit modules with the same power switches are connected in parallel at the input and output sides to reduce the current stresses on the output diodes and the primary and secondary windings of the transformers. An active snubber is connected between two power transformers to achieve a transformer flux reset, to limit the voltage spikes on power switches and to achieve the ZVS turn-on of switches. In the secondary side, an output voltage doubler is used to achieve an output voltage step-up. The circuit configuration, operation principles, mathematical analysis and design considerations of the proposed converter are analyzed in detail. Experiments based on a 340W laboratory prototype are presented to verify the circuit performance.

\section{Circuit Configuration}

The circuit configuration of the proposed converter is shown in Fig. 1. There are two modules connected in parallel to share the load current. $V_{\text {in }}$ is the input voltage, $T_{1}$ and $T_{2}$ are the isolated transformers, $L_{r 1}$ and $L_{r 2}$ are the resonant inductances, $L_{m 1}$ and $L_{m 2}$ are the magnetizing inductances, and $S_{1}$ and $S_{2}$ are the main and auxiliary switches. $D_{S 1}$ and $D_{S 2}$ are the antiparallel diodes of $S_{1}$ and $S_{2}$, respectively. An active snubber including $S_{2}$ and $C_{c}$ is connected between the two transformers $T_{1}$ and $T_{2}$ to limit the voltage stress of the power switches $S_{1}$ and $S_{2}$ and to implement the flux reset of $T_{1}$ and $T_{2}$. During the transition interval of $S_{1}$ and $S_{2}$, the capacitors $C_{S 1}$ and $C_{S 2}$ 


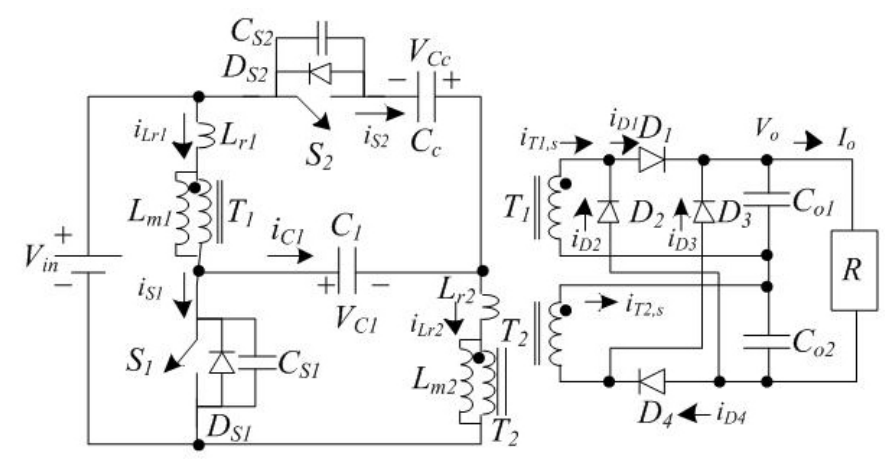

Fig. 1. Circuit Configuration of the proposed converter.

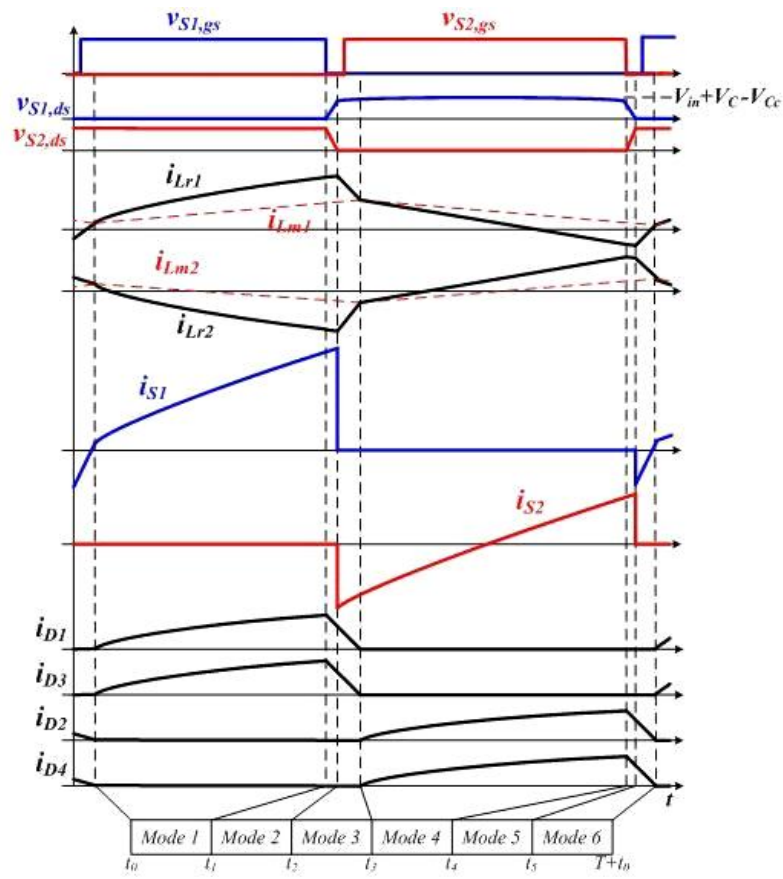

Fig. 2. Key waveforms of the proposed converter.

and the inductors $L_{r 1}$ and $L_{r 2}$ are resonant to allow the ZVS turn-on feature on the switches $S_{1}$ and $S_{2}$. Thus, the switching losses and the thermal stresses of the semiconductors and the transformers are reduced. In the secondary side of $T_{1}$ and $T_{2}$, a voltage doubler rectifier is used to obtain a stable output voltage $V_{o}$. The PWM signals of $S_{1}$ and $S_{2}$ are complementary to each other with a small delay time which can be generated from a general PWM IC or from an active clamp PWM IC with an isolated gate driver.

\section{OPERATION PRINCIPLE}

Based on the on and off states of the switches $S_{1}$ and $S_{2}$ and the diodes $D_{1} \sim D_{4}$, there are six operating modes in the proposed converter during one switching cycle. Fig. 2 shows the key waveforms of the proposed converter and Fig. 3 gives the topological operating modes in a switching cycle. Before the system analysis, the following assumptions are made:

- $\delta$ is a duty cycle of the main switch $S_{1}$;

- The conduction times of $S_{1}$ and $S_{2}$ are $\delta T_{s}$ and (1- $\left.\delta\right) T_{s}$, where $T_{s}$ is the switching period;

- The capacitances $C, C_{c}, C_{o 1}$ and $C_{o 2}$ are much larger such that the voltages $V_{C}, V_{C c}, V_{o 1}$ and $V_{o 2}$ are assumed to be constant;

- The capacitances $C_{S 1}$ and $C_{S 2}$ are less than the capacitances $C$ and $C_{c}$;

- The turns ratio of $T_{1}$ and $T_{2}$ are identical $n=n_{T 1}=n_{T 2}=N_{p} / N_{s}$;

- The resonant inductances $L_{r 1}=L_{r 2}=L_{r}$ are much less than the magnetizing inductances $L_{m 1}=L_{m 2}=L_{m}$;

- In the steady state, the average capacitor voltage $V_{C}=V_{i n}$.

Before time $t_{0}$, the switch $S_{1}$ is in the on-state. Since the inductor current $i_{L r 1}<i_{L m 1}$ and the inductor current $i_{L r 2}>i_{L m 2}$, the secondary winding current $i_{T 1, s}$ is negative and the secondary winding current $i_{T 2, s}$ is positive, respectively. Thus, the diodes $D_{2}$ and $D_{4}$ are conducting. The primary voltage $v_{L m 1}=-n V_{o 2}$ and the primary voltage $v_{L m 2}=n V_{o 2}$. The inductor current $i_{L r 1}$ increases and the inductor current $i_{L r 2}$ decreases.

Mode 1 [ $\left.\boldsymbol{t}_{0} \leq \boldsymbol{t}<\boldsymbol{t}_{1}\right]$ : At time $t_{0}$, the inductor current $i_{L r 1}>$ $i_{L m 1}$ and the inductor current $i_{L r 2}<i_{L m 2}$, respectively. Thus the diodes $D_{1}$ and $D_{3}$ are conducting in this mode. The primary voltage $v_{L m 1}=n V_{o 1}$ and the primary voltage $v_{L m 2}=-n V_{o 1}$. Since the switch $S_{1}$ is in the on-state, the inductor currents $i_{L r 1}$ and $i_{L r 2}$ are expressed as:

$$
\begin{aligned}
& i_{L r 1}(t) \approx i_{L r 1}\left(t_{0}\right)+\frac{V_{i n}-n V_{o 1}}{L_{r}}\left(t-t_{0}\right) \\
& i_{L r 2}(t) \approx i_{L r 2}\left(t_{0}\right)+\frac{n V_{o 1}-V_{C}}{L_{r}}\left(t-t_{0}\right) .
\end{aligned}
$$

Since $V_{i n}>n V_{o 1}$, the inductor current $i_{L r 1}$ increases and the inductor current $i_{L r 2}$ decreases. The magnetizing currents $i_{L m 1}$ and $i_{L m 2}$ are given as:

$$
\begin{gathered}
i_{L m 1}(t)=i_{L m 1}\left(t_{0}\right)+n V_{o 1}\left(t-t_{0}\right) / L_{m} \\
i_{L m 2}(t)=i_{L m 2}\left(t_{0}\right)-\frac{n V_{o 1}}{L_{m}}\left(t-t_{0}\right) .
\end{gathered}
$$

Power is delivered from the input terminal voltage $V_{\text {in }}$ to the output capacitor $C_{o 1}$ through $T_{1}, S_{1}$ and $D_{1}$. The energy stored in the capacitor $C$ also delivers power to the capacitor $C_{o 1}$ through $T_{2}, S_{1}$ and $D_{3}$. The secondary diode currents $i_{D 1}$ and $i_{D 3}$ are given as:

$$
\begin{aligned}
& i_{D 1}(t)=n\left(i_{L r 1}(t)-i_{L m 1}(t)\right) \\
& i_{D 3}(t)=n\left(i_{L m 2}(t)-i_{L r 2}(t)\right) .
\end{aligned}
$$

The switch current $i_{S 1}$ is expressed as:

$$
\begin{aligned}
i_{S 1}(t) & =i_{L r 1}(t)-i_{L r 2}(t) \\
& \approx i_{L r 1}\left(t_{0}\right)-i_{L r 2}\left(t_{0}\right)+\frac{2\left(V_{i n}-n V_{o 1}\right)}{L_{r}}\left(t-t_{0}\right) .
\end{aligned}
$$

This mode ends at time $t_{1}$ when $S_{1}$ is turned off.

Mode $2\left[t_{1} \leq t<t_{2}\right]$ : At time $t_{1}, S_{1}$ is turned off. $C_{S 1}$ is charged from the zero voltage and $C_{S 2}$ is discharged from $V_{i n}+V_{C}-V_{C c}$. The components $L_{r 1}, L_{r 2}, C_{S 1}$ and $C_{S 2}$ are resonant in this mode. Since the time interval in this mode is negligible when compared to the switching period $T_{s}$, the primary currents $i_{L r 1}$ and $i_{L r 2}$ are almost constant and $C_{S 1}$ and $C_{S 2}$ are linearly charged and discharged, respectively. The diodes $D_{1}$ and $D_{3}$ are still conducting in this mode. At time $t_{2}$, the capacitor voltage $v_{C S 2}$ decreases to zero and the capacitor voltage $v_{C S 1}$ increases to $V_{i n}+V_{C}-V_{C c}$. When the voltage $v_{S 2, d s}$ 
(or $v_{C S 2}$ ) becomes zero at time $t_{2}$, the anti-parallel diode $D_{S 2}$ of the switch $S_{2}$ is conducting.

Mode 3 [ $\boldsymbol{t}_{2} \leq \boldsymbol{t}<\boldsymbol{t}_{3}$ ]: At time $t_{2}$, the anti-parallel diode $D_{S 2}$ is conducting and the switching current $i_{S 2}$ is negative. Thus the switch $S_{2}$ can be turned on in this mode to realize ZVS. Since the diodes $D_{1}$ and $D_{3}$ are still conducting in this mode, the magnetizing current $i_{L m 1}$ increases and the magnetizing current $i_{L m 2}$ decreases, respectively. The inductor voltage $v_{L r 1}=V_{C c^{-}}$ $V_{C}-n V_{o 1}<0$ and the inductor voltage $v_{L r 2}=n V_{o 1}+V_{i n}-V_{C c}>0$. Therefore, the inductor current $i_{L r 1}$ decreases and the inductor current $i_{L r 2}$ increases. At time $t_{3}, i_{L r 1}=i_{L m 1}$ and $i_{L r 2}=i_{L m 2}$. Then the diodes $D_{1}$ and $D_{3}$ are off and the diodes $D_{2}$ and $D_{4}$ are conducting.

Mode 4 [ $\left.\boldsymbol{t}_{3} \boldsymbol{t}<\boldsymbol{t}_{4}\right]$ : In this mode, $i_{L r 1}<i_{L m 1}$ and $i_{L r 2}>i_{L m 2}$. Thus the diodes $D_{1}$ and $D_{3}$ are off and the diodes $D_{2}$ and $D_{4}$ are conducting. The auxiliary switch $S_{2}$ is still in the on-state. The magnetizing voltage $v_{L m 1}=-n V_{o 2}$ and the magnetizing voltage $v_{L m 2}=n V_{o 2}$. Thus the magnetizing current $i_{L m 1}$ decreases and the magnetizing current $i_{L m 2}$ increases, respectively. The inductor voltage $v_{L r 1}=V_{C C}+n V_{o 2}-V_{C}<0$ and the inductor voltage $v_{L r 2}=V_{i n}-V_{C c}-n V_{o 2}>0$. Thus the inductor current $i_{L r 1}$ decreases and the inductor current $i_{L r 2}$ increases. The power is transferred from the input terminal $V_{i n}$ to the output capacitor $C_{o 2}$ through $S_{2}, C_{c}, L_{r 2}, T_{2}, D_{4}$ and $C_{o 2}$. The switch current $i_{S 2}=i_{L r 2}-i_{L r 1}$. This mode ends at time $t_{4}$ when $S_{2}$ is turned off.

Mode 5 [ $\left.\boldsymbol{t}_{4} \boldsymbol{t}<\boldsymbol{t}_{5}\right]:$ At time $t_{4}$, the auxiliary switch $S_{2}$ is turned off. Since $i_{L r 2}\left(t_{4}\right)-i_{L r 1}\left(t_{4}\right)>0$, the capacitor $C_{S 2}$ is charged and the capacitor $C_{S 1}$ is discharged. The drain voltage $V_{S 1, d}$ decreases from $V_{i n}+V_{C}-V_{C c}$ and the drain voltage $V_{S 2, d}$ increases from zero voltage. Since the time interval in this mode is negligible when compared to the switching period $T_{s}$, the inductor currents $i_{L r 1}$ and $i_{L r 2}$ are almost constant and $C_{S 1}$ and $C_{S 2}$ are linearly discharged and charged, respectively. The diodes $D_{2}$ and $D_{4}$ are still conducting in this mode. At time $t_{5}$, the capacitor voltage $v_{C S 1}$ decreases to zero and the capacitor voltage $v_{C S 2}$ increases to $V_{i n}+V_{C}-V_{C c}$. When the voltage $v_{S 1, d s}$ (or $v_{C S 1}$ ) becomes zero at time $t_{5}$, the anti-parallel diode $D_{S 1}$ of switch $S_{1}$ is conducting.

Mode $6\left[\boldsymbol{t}_{5} \boldsymbol{t}<\boldsymbol{T}+t_{0}\right]$ : At time $t_{5}$, the anti-parallel diode $D_{S 1}$ is conducting and the switching current $i_{S 1}$ is negative. Thus the switch $S_{1}$ can be turned on at this instant to achieve ZVS. Since the diodes $D_{2}$ and $D_{4}$ are still conducting in this mode, the magnetizing current $i_{L m 1}$ decreases and the magnetizing current $i_{L m 2}$ increases. The inductor voltage $v_{L r 1}=V_{i n}+n V_{o 2}>0$ and the inductor voltage $v_{L r 2}=-n V_{o 2}-V_{C c}<0$. Therefore, the inductor current $i_{L r 1}$ increases and the inductor current $i_{L r 2}$ decreases. At time $T+t_{0}, i_{L r 1}=i_{L m 1}$ and $i_{L r 2}=i_{L m 2}$. Then the diodes $D_{2}$ and $D_{4}$ are off, and the diodes $D_{1}$ and $D_{3}$ are conducting. Then, the circuit operation of the proposed converter in a switching cycle is completed.

\section{Circuit Analysis}

The transition intervals in modes 2 and 5 are much shorter than the other time intervals. Thus these two modes to derive the dc voltage conversion ratio of the proposed converter were neglected. In mode $1, S_{1}$ is on. The time interval in this mode is $\left(\delta-\delta_{6}\right) T_{s}$, where $\delta$ is the duty cycle of $S_{1}$, $\delta_{6}$ is the duty loss in mode 6 , and $T_{s}$ is the switching period. The voltages on $L_{m 1}$ and $L_{m 2}$ are $n V_{o 1}$ and $-n V_{o 1}$. Thus the inductor voltage $v_{L r 1}=V_{i n}-n V_{o 1}$ and the inductor voltage $v_{L r 2}=-V_{C}+n V_{o 1}=-V_{i n}+n V_{o 1}$. In mode $3, S_{2}, D_{1}$ and $D_{3}$ are on such that $v_{L m 1}=n V_{o 1}, v_{L m 2}=-n V_{o 1}, v_{L r 1}=V_{C c^{-}} V_{C^{-}}$ $n V_{o 1}$ and $v_{L r 2}=V_{i n}+n V_{o 1}-V_{C c}$. The time interval in this mode is $\delta_{3} T_{s}$. In mode $4, S_{2}, D_{2}$ and $D_{4}$ are on such that $v_{L m 1}=-$ $n V_{o 2}, v_{L m 2}=n V_{o 2}, v_{L r 1}=-V_{C}+n V_{o 2}+V_{C c}$ and $v_{L r 2}=V_{i n}-n V_{o 2}-$ $V_{C c}$. The time interval in this mode is $\left(1-\delta-\delta_{3}\right) T_{s}$. In mode $6, S_{1}, D_{2}$ and $D_{4}$ are on such that $v_{L m 1}=-n V_{o 2}, v_{L m 2}=n V_{o 2}$, $v_{L r 1}=V_{i n}+n V_{o 2}$ and $v_{L r 2}=-V_{C}-n V_{o 2}$. The time interval in this mode is $\delta_{6} T_{s}$. Based on the voltage-second balance on the secondary windings of $T_{1}$ and $T_{2}$, the output capacitor voltages are given as:

$$
\begin{gathered}
V_{o 1}=\left(1-\delta-\delta_{3}+\delta_{6}\right) V_{o} \\
V_{o 2}=\left(\delta+\delta_{3}+\delta_{6}\right) V_{o} .
\end{gathered}
$$

Based on the volt-second balance on the inductors $L_{r 1}$ and $L_{m 1}$ and the inductors $L_{r 2}$ and $L_{m 2}$, the voltages $V_{C c}$ and $V_{C}$ of capacitors $C_{c}$ and $C$ are expressed as:

$$
\begin{gathered}
V_{C c}=(1-2 \delta) V_{i n} /(1-\delta) \\
V_{C}=V_{i n} .
\end{gathered}
$$

The voltage conversion ratio $M$ of the proposed converter can be expressed as:

$$
\begin{aligned}
& M=\frac{V_{o}+V_{f}}{V_{i n}} \approx \frac{1}{n\left(1-\delta-\delta_{3}+\delta_{6}\right)\left(1+L_{L r} / L_{m}\right)} \\
& \approx \frac{1}{n\left(1-\delta-\delta_{3}+\delta_{6}\right)}
\end{aligned}
$$

where $V_{f}$ is the voltage drop on the diodes $D_{1} \sim D_{4}$. The peak diode current $i_{D 2, \text { peak }}$ can be expressed as:

$$
i_{D 2, p e a k}=I_{o} /\left(1-\delta-\delta_{3}+\delta_{6}\right) .
$$

The duty cycle loss in mode 6 can be obtained by the diode current $i_{D 2}$ from the peak diode current $i_{D 2, \text { peak }}$ to zero.

$$
\frac{i_{D 2, p e a k}}{n}=\frac{V_{i n}+n V_{o}\left(\delta+\delta_{3}-\delta_{6}\right)}{L_{r}} \delta_{6} T_{s} .
$$

If $\delta_{3}=\delta_{6}$ is assumed, then the duty cycle loss $\delta_{6}$ can be obtained from (13) and (14).

$$
\delta_{6}=\frac{I_{o} L_{r} f_{s}}{n\left(V_{i n}+n V_{o} \delta\right)(1-\delta)} .
$$

Based on the assumption of $\delta_{3}=\delta_{6}$, the following equations can be obtained from (8)-(13).

$$
\begin{gathered}
V_{o 1} \approx(1-\delta) V_{o} \\
V_{o 2} \approx \delta V_{o} \\
M=\frac{V_{o}+V_{f}}{V_{\text {in }}} \approx \frac{1}{n(1-\delta)} \\
i_{D 2, \text { peak }}=i_{D 4, \text { peak }} \approx I_{o} /(1-\delta) \\
i_{D 1, \text { peak }}=i_{D 3, \text { peak }} \approx I_{o} / \delta .
\end{gathered}
$$

The average currents on the rectifier diodes $D_{1} \sim D_{4}$ are equal to $I_{o} / 2$. The voltage stresses of the output diodes $D_{1} \sim D_{4}$ 


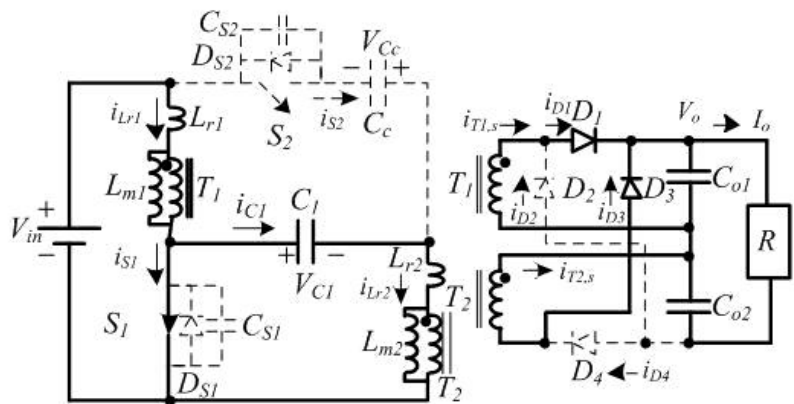

(a)

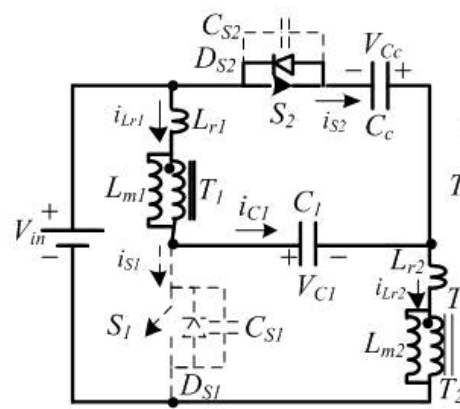

(c)

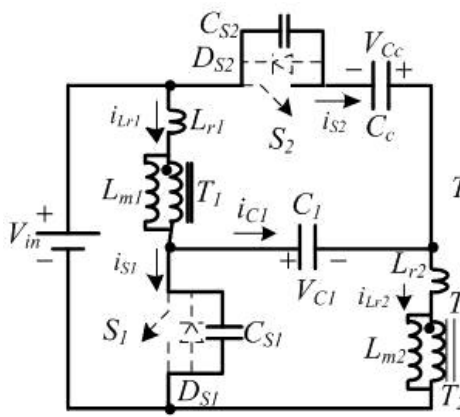

(e)

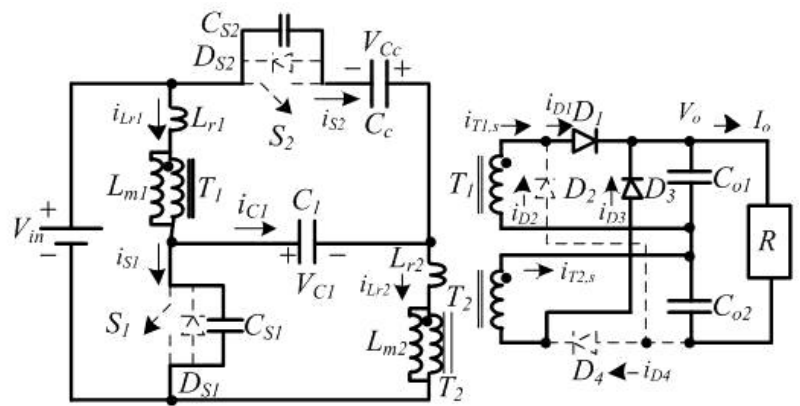

(b)

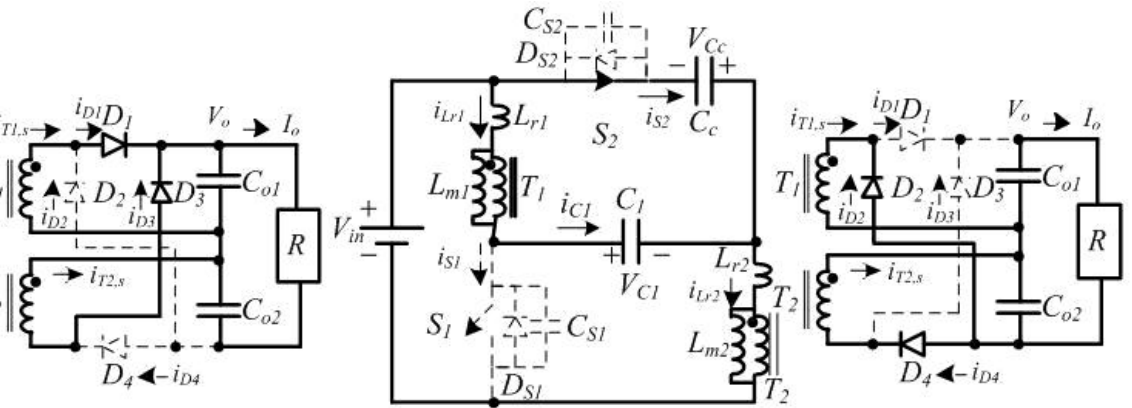

(d)

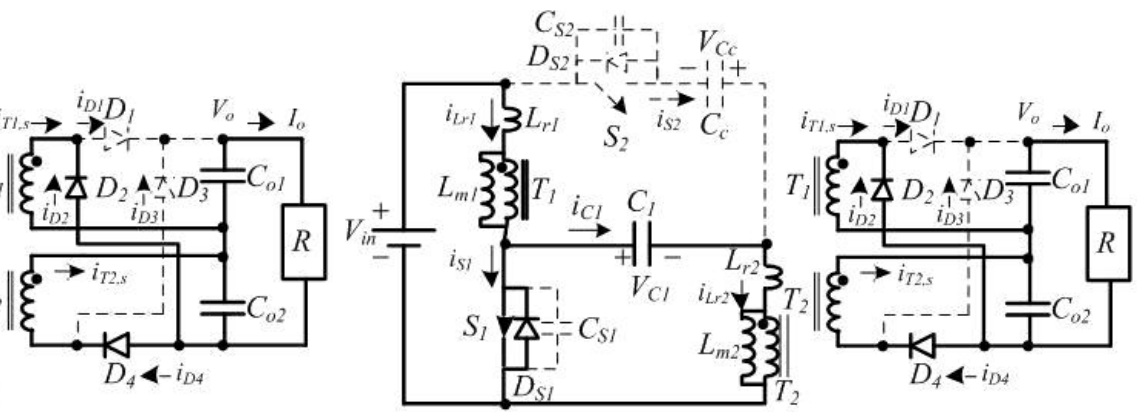

(f)

Fig. 3. Equivalent circuits of the proposed converter during a switching cycle (a) mode 1 (b) mode 2 (c) mode 3 (d) mode 4 (e) mode 5 (f) mode 6.

are equal to $V_{o}+V_{f}$. To meet the current-second balance for $C$ and $C_{c}$, the dc magnetizing currents $i_{L m 1, a v}$ of $T_{1}$ and $i_{L m 2, a v}$ of $T_{2}$ are given as:

$$
\begin{gathered}
i_{L m 1, a v}=\frac{I_{O}}{n(1-\delta)} \\
i_{L m 2, a v}=0 .
\end{gathered}
$$

The ripple components of $i_{L m 1}$ and $i_{L m 2}$ are expressed as:

$$
\begin{gathered}
\Delta i_{L m 1}=\frac{n V_{o 1}}{L_{m}}\left(\delta-\delta_{6}\right) T_{s} \approx \frac{n \delta(1-\delta) V_{o} T_{s}}{L_{m}} \\
\Delta i_{L m 2} \approx \frac{n \delta(1-\delta) V_{o} T_{s}}{L_{m}} .
\end{gathered}
$$

The peak and root-mean-square (rms) values of the switching currents can be expressed as:

$$
i_{S 1, \max }=i_{S 2, \max } \approx \frac{I_{o}}{n(1-\delta)}+\frac{n \delta(1-\delta) V_{o} T_{S}}{L_{m}}+\frac{2 I_{o}}{\delta}
$$

$$
\begin{aligned}
& i_{S 1, r m s} \approx \sqrt{\delta\left[\frac{I_{o}}{n(1-\delta)}\right]^{2}+\frac{\delta}{3}\left(\frac{n \delta(1-\delta) V_{o} T_{s}}{L_{m}}\right)^{2}+\frac{\delta}{12}\left(\frac{I_{o}}{\delta}\right)^{2}} \\
& i_{S 2, r m s} \approx \sqrt{\frac{1-\delta}{3}\left(\frac{n \delta(1-\delta) V_{o} T_{s}}{L_{m}}\right)^{2}+\frac{1-\delta}{12}\left(\frac{I_{o}}{1-\delta}\right)^{2}}
\end{aligned}
$$

The voltage stresses of $S_{1}$ and $S_{2}$ can be obtained from modes 4 and 1 .

$$
V_{S 1, \text { stress }}=V_{S 2, \text { stress }}=V_{\text {in }}+V_{C}-V_{C c} \approx \frac{V_{\text {in }}}{1-\delta} .
$$

From (28), it can be seen that the voltage stresses of $S_{1}$ and $S_{2}$ are related to the input voltage $V_{i n}$ and the duty cycle $\delta$. Basically, the ZVS condition of the main switch $S_{1}$ is more difficult to realize than that of the auxiliary switch $S_{2}$. Thus only the ZVS condition of the switch $S_{1}$ is considered. At time $t_{4}$, the inductor currents $i_{L r 1}(t)$ and $i_{L r 2}(t)$ are approximately given as:

$$
i_{L r 1}\left(t_{4}\right) \approx-n \delta(1-\delta) V_{o} T_{S} /\left(2 L_{m}\right)
$$




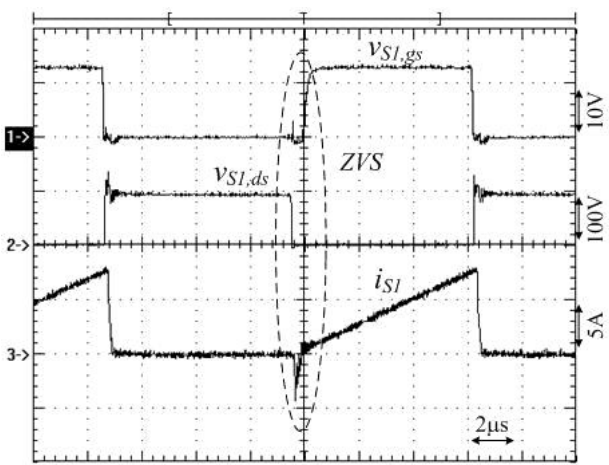

(a)

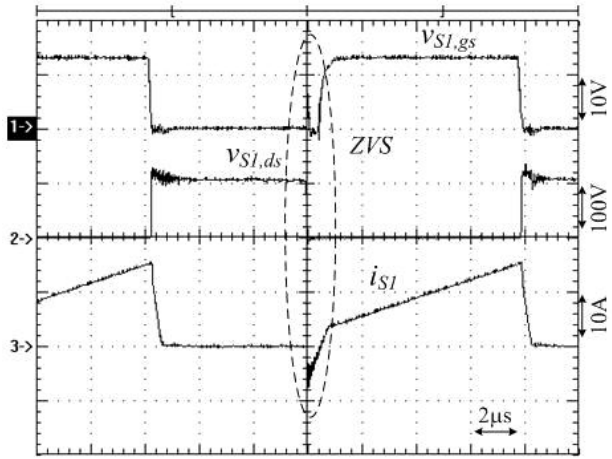

(b)

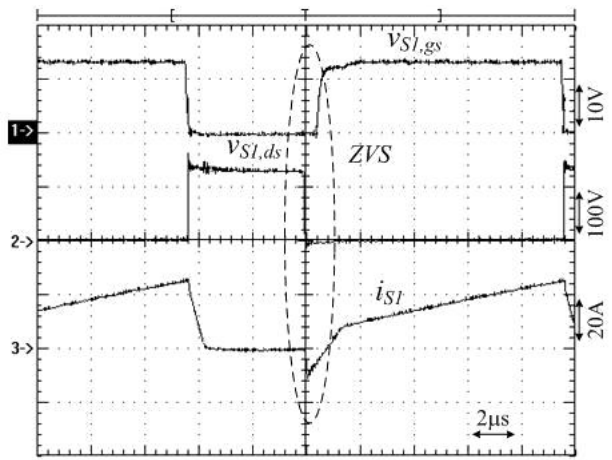

(c)

Fig. 4. Measured waveforms of gate voltage, drain voltage and switch current of switch $S_{1}$ at (a) $30 \%$ load (b) $60 \%$ load (c) $100 \%$ load.

$$
i_{L r 2}\left(t_{4}\right) \approx \frac{n \delta(1-\delta) V_{i o} T_{S}}{2 L_{m}}+\frac{I_{o}}{n(1-\delta)} .
$$

To ensure the ZVS turn-on of the switch $S_{1}$, the energy stored in the inductors $L_{r 1}$ and $L_{r 2}$ must be greater than the energy stored in the capacitors $C_{S 1}$ and $C_{S 2}$ in mode 4. Thus the ZVS condition of $S_{1}$ is expressed as:

$$
L_{r}\left(i_{L r 1}^{2}\left(t_{4}\right)+i_{L r 2}^{2}\left(t_{4}\right)\right) \geq C_{S 1} V_{C s 1}^{2} \approx \frac{C_{S 1} V_{i n}^{2}}{(1-\delta)^{2}} .
$$

Thus the minimum inductance $L_{r}$ is expressed in (32) to realize the ZVS turn-on of $S_{1}$.

$$
\begin{aligned}
L_{r} & \geq \frac{C_{S} V_{i n}^{2} /(1-\delta)^{2}}{i_{L r 1, Z V S}^{2}\left(t_{4}\right)+i_{L r 2, Z V S}^{2}\left(t_{4}\right)} \\
& \approx \frac{C_{S} V_{i n}^{2} /(1-\delta)^{2}}{\left(\frac{n \delta(1-\delta) V_{o} T_{s}}{2 L_{m}}\right)^{2}+\left(\frac{n \delta(1-\delta) V_{o} T_{s}}{2 L_{m}}+\frac{I_{o}}{n(1-\delta)}\right)^{2}} .
\end{aligned}
$$

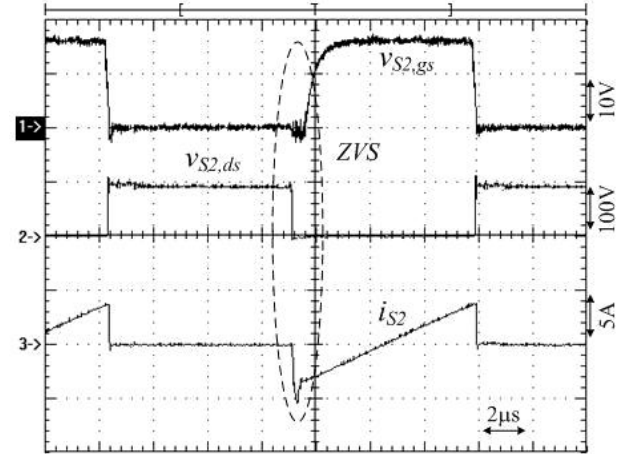

(a)

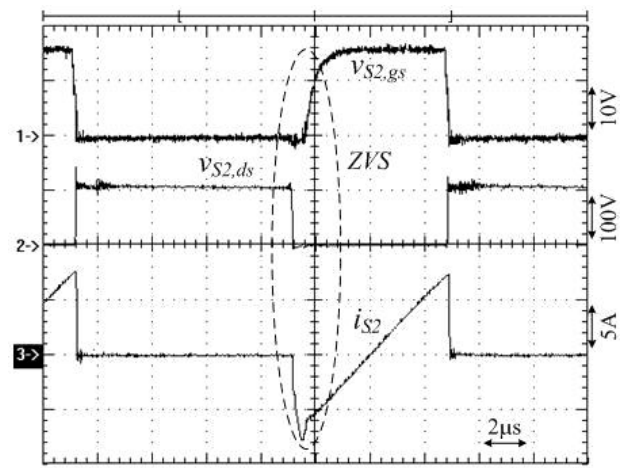

(b)

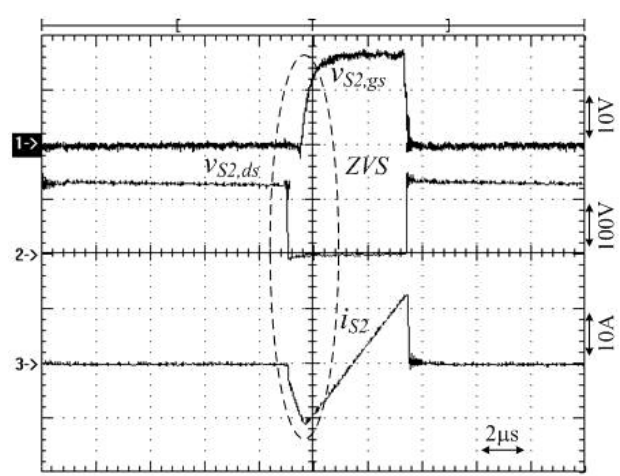

(c)

Fig. 5. Measured waveforms of gate voltage, drain voltage and switch current of switch $S_{2}$ at (a) $30 \%$ load (b) $60 \%$ load (c) $100 \%$ load.

The peak-to-peak ripple current on $C$ is given as:

$$
\Delta i_{C} \approx \Delta i_{L m 2}+I_{o} /(n \delta) \text {. }
$$

If the ripple capacitor voltage $\Delta v_{C}$ is given, then the capacitance of $C$ can be obtained as:

$$
C \approx \Delta i_{C} \delta T / \Delta v_{C} .
$$

\section{EXPERIMENTAL RESULTS}

A laboratory prototype circuit with a $340 \mathrm{~W}$ (200V/1.7A) rated power was built to verify the effectiveness of the proposed converter. The nominal input terminal voltage $V_{i n}$ is $48 \mathrm{~V}$ and the minimum and maximum input voltages are $36 \mathrm{~V}$ and $60 \mathrm{~V}$, respectively. The proposed converter is operated at a switching frequency $f_{s}=70 \mathrm{kHz}$. An EI-40 core was used for the transformers $T_{1}$ and $T_{2}$. The primary winding turns $N_{p}$ are 18 and the secondary winding turns $N_{s}$ are 50. The 


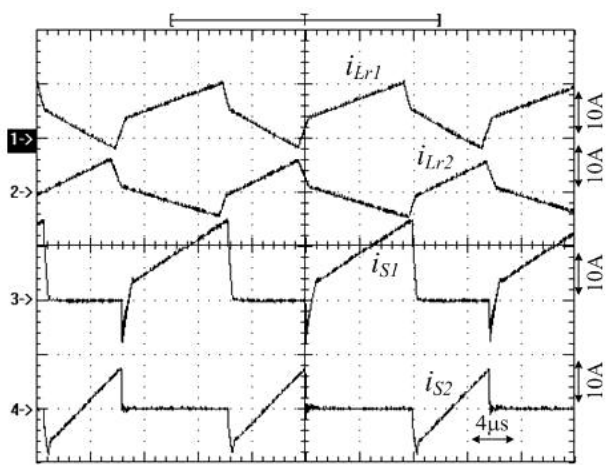

(a)

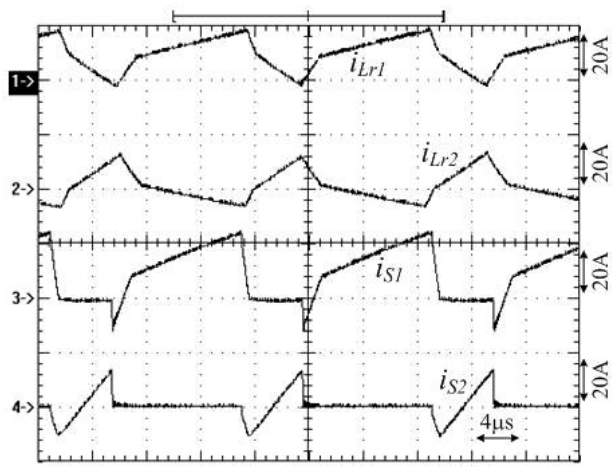

(b)

Fig. 6. Measured waveforms of inductor currents and switch currents at (a) $60 \%$ load (b) $100 \%$ load.

magnetizing inductances $L_{m}$ of $T_{1}$ and $T_{2}$ are $100 \mathrm{mH}$. The resonant inductances of $L_{r 1}$ and $L_{r 2}$ are $10 \mathrm{mH}$. The output filter capacitances $C_{o 1}$ and $C_{o 2}$ are $330 \mathrm{mF} / 420 \mathrm{~V}$. IRFP264N MOSFETs are used for the switches $S_{1}$ and $S_{2}$ and ER605 fast recovery diodes are adopted for the diodes $D_{1} \sim D_{4}$. the capacitances of $C_{c}$ and $C$ are $16 \mathrm{mF}$. A type II voltage controller was adopted to regulate the output voltage using IC UCC2893 PWM control. Fig. 4 shows the measured gate voltage $v_{S 1, g}$, the drain voltage $v_{S 1, d}$ and the switch current $i_{S 1}$ of the switch $S_{1}$ at $30 \%, 60 \%$ and $100 \%$ load conditions, respectively. Before the switch $S_{1}$ is turned on, the switch current $i_{S 1}$ is negative to discharge the capacitor $C_{S 1}$. Thus the drain voltage $v_{S 1, d}$ is decreased to zero and the anti-parallel diode $D_{S 1}$ is conducting. Therefore, the switch $S_{1}$ is turned on at this instant to achieve ZVS. Fig. 5 shows the measured gate voltage $v_{S 2, g}$, the drain voltage $v_{S 2, d}$ and the switch current $i_{S 2}$ of the switch $S_{2}$ at $30 \%, 60 \%$ and $100 \%$ load conditions, respectively. Similarly, $S_{2}$ is also turned on at ZVS.

Fig. 6 shows the primary winding currents $i_{L r 1}$ and $i_{L r 2}$, and the switch currents $i_{S 1}$ and $i_{S 2}$ at $60 \%$ and $100 \%$ load conditions. When $S_{1}$ is in the on state, the switch current $i_{S 2}$ is zero, the inductor current $i_{L r 1}$ increases and the inductor current $i_{L r 2}$ decreases, and the switch current $i_{S 1}=i_{L r 1}-i_{L r 2}$. When $S_{1}$ is in the off state and $S_{2}$ is in the on state, the switch current $i_{S 1}$ is zero. The inductor current $i_{L r 1}$ decreases, the inductor current $i_{L r 2}$ increases, and the switch current $i_{S 2}=i_{L r 2}-$ $i_{L r 1}$. Fig. 7 illustrates the measured results of the gate voltages $v_{S 1, g s}$ and $v_{S 2, g s}$, the clamp voltage $v_{C c}$ and the capacitor voltage $v_{C}$ at $30 \%, 60 \%$ and $100 \%$ load conditions. It is clear that the clamp voltage $v_{C c}$ is related to the duty cycle of the

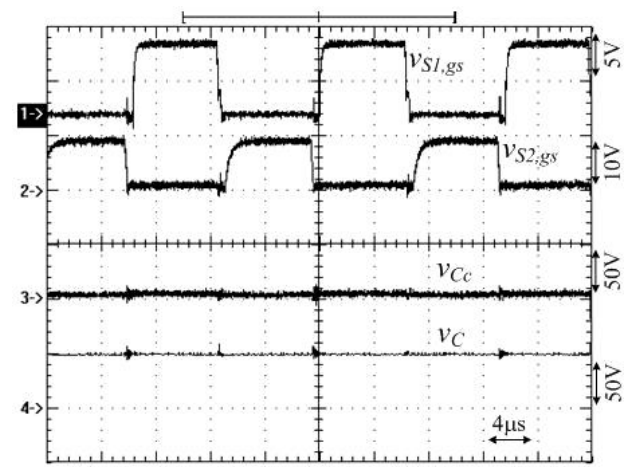

(a)

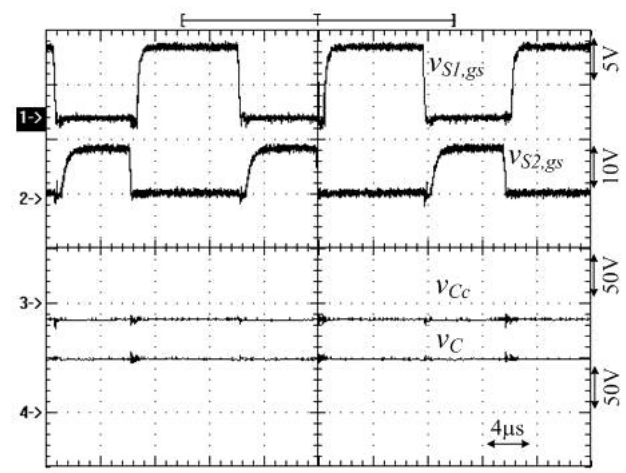

(b)

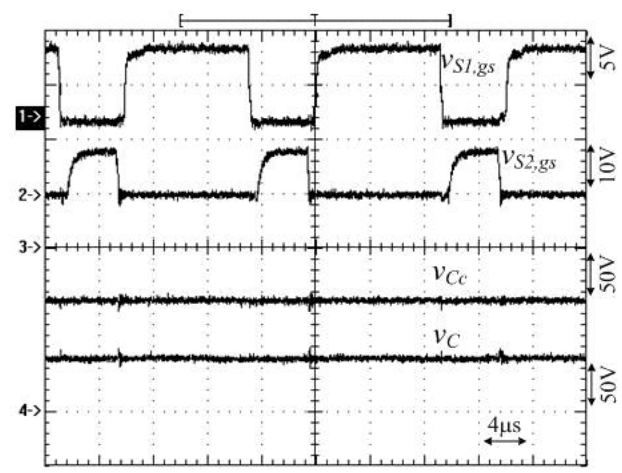

(c)

Fig. 7. Measured waveforms of gate voltages $v_{S 1, g s} v_{S 2, g s}, v_{C c}$ and $v_{C}$ at (a) $30 \%$ load (b) $60 \%$ load (c) $100 \%$ load.

switch $S_{1}$. If the duty cycle $\delta$ is greater than 0.5 , then $v_{C c}$ is a negative voltage. On the other hand, $v_{C c}$ is positive voltage if $\delta$ is less than 0.5 .

Figs. 8 and 9 show the measured waveforms of the gate voltage $v_{S 1, g s}$, the secondary winding currents $i_{T 1, s}$ and $i_{T 2, s}$ and the diode currents $i_{D 1} \sim i_{D 4}$ at $60 \%$ and $100 \%$ load conditions. When $S_{1}$ is in the on state, the secondary winding current $i_{T 1, s}$ is positive and the secondary winding current $i_{T 2, s}$ is negative. Thus the diodes $D_{1}$ and $D_{3}$ are conducting. When $S_{1}$ is in the off state, the secondary winding current $i_{T 1, s}$ is negative and the secondary winding current $i_{T 2, s}$ is positive. Thus the diodes $D_{2}$ and $D_{4}$ are conducting. Fig. 10 gives the measured waveforms of gate voltage $v_{S 1, g s}$ and the output capacitor voltages $V_{o 1}$ and $V_{o 2}$ at $60 \%$ and $100 \%$ load conditions. It is clear that the capacitor voltages $V_{o 1}$ and $V_{o 2}$ are related to the duty cycle of the switch $S_{1}$. Fig. 11 shows the 


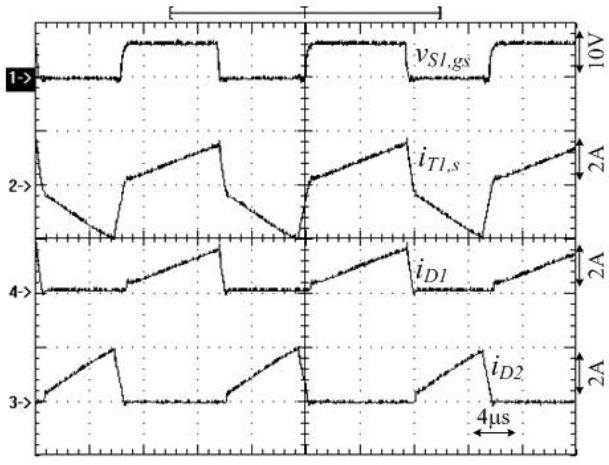

(a)

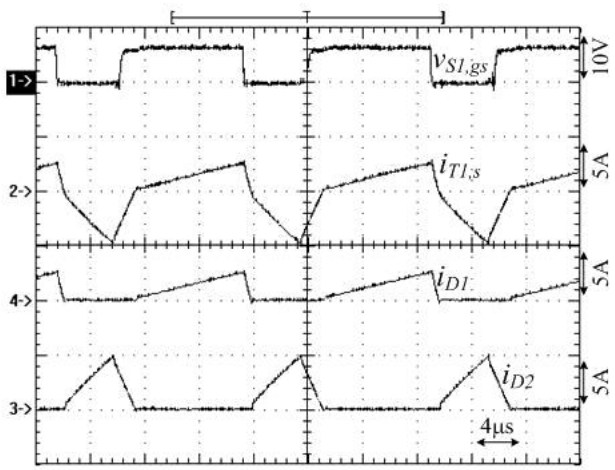

(b)

Fig. 8. Measured waveforms of gate voltage $v_{S 1, g s}$ and the secondary side currents of $T_{1}$ at (a) $60 \%$ load (b) $100 \%$ load.

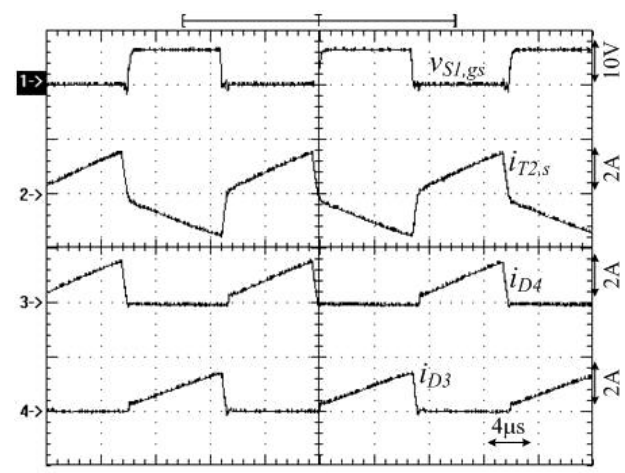

(a)

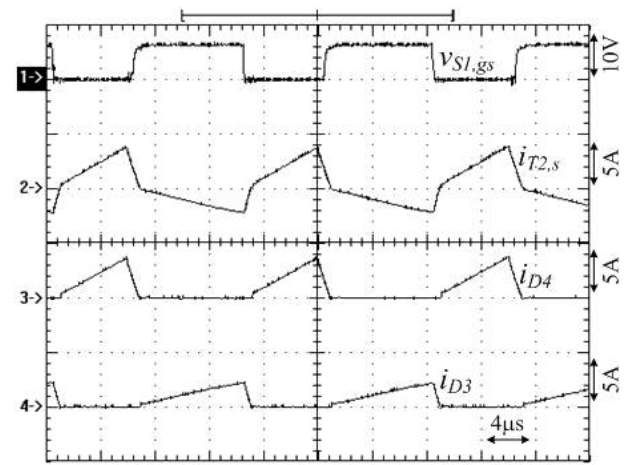

(b)

Fig. 9. Measured waveforms of gate voltage $v_{S 1, g s}$ and the secondary side currents of $T_{2}$ at (a) $60 \%$ load (b) $100 \%$ load.

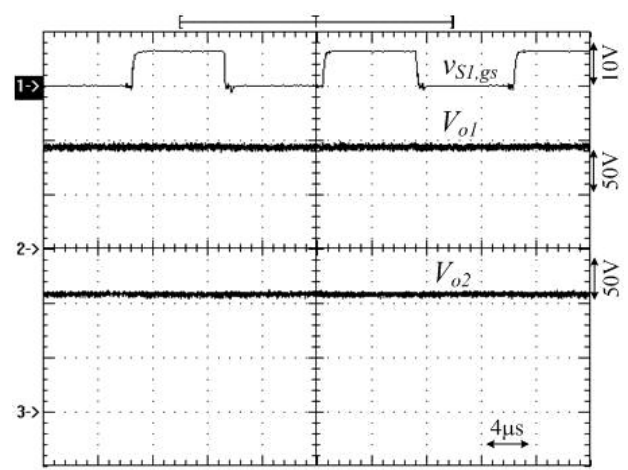

(a)

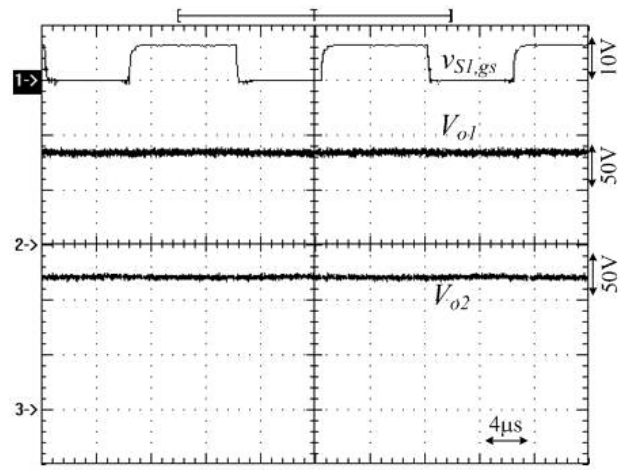

(b)

Fig. 10. Measured waveforms of gate voltage $v_{S 1, g s}$ and output capacitor voltages $V_{o 1}$ and $V_{o 2}$ at (b) $30 \%$ load (b) $100 \%$ load.

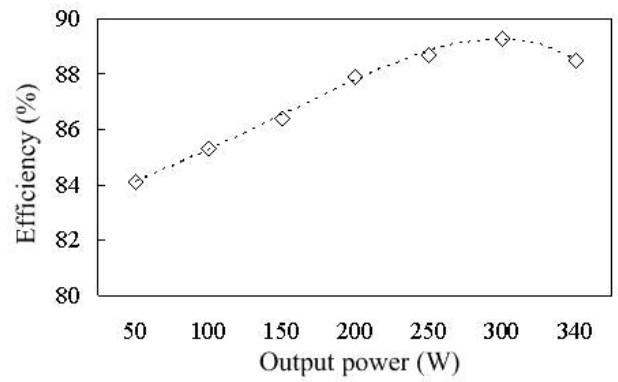

Fig. 11. Measured efficiencies of the proposed converter at different load conditions.

measured efficiencies of the proposed converter for different load conditions. The maximum efficiency of the proposed converter is $89.3 \%$ at $90 \%$ of full load. If the lower turn-on resistance of the MOSFETs is available and the skin effect of transformer winding is considered in the design of the circuit, the circuit efficiency of the adopted converter can be increased by about $3 \%-5 \%$.

\section{CONCLUSION}

In this paper, a parallel soft-switching converter with an output voltage doubler is proposed. An active snubber is adopted to realize the transformer flux reset, to limit the peak voltage on the semiconductors, and to achieve ZVS turn-on for the main and auxiliary switches. Thus the converter efficiency is increased. The two circuit modules are connected in parallel with the same switches to achieve load current sharing. A circuit analysis and a design example of the proposed circuit are discussed and presented in detail. Finally, experiments 
based on a $340 \mathrm{~W}$ laboratory prototype have been provided to verify the theoretical analysis and the performance of the proposed converter.

\section{REFERENCES}

[1] B.-C. Hyeon and B.-H. Cho, "A tightly regulated triple output asymmetrical half bridge flyback converter," Journal of Power Electronics, Vol. 10, No. 1, pp. 14-20, Feb. 2010.

[2] B.-R. Lin and C.-H. Tseng, "Analysis of parallel-connected asymmetrical soft-switching converter," IEEE Trans. Ind. Electron., Vol. 54, No. 3, pp. 1642-1653, May 2007.

[3] J.-P. Lee, B.-D. Min, T.-J. Kim, D.-W. Yoo, and J.-Y. Yoo, "inputseries-output-parallel connected $\mathrm{dc} / \mathrm{dc}$ converter for a photovoltaic pcs with high efficiency under a wide load range," Journal of Power Electronics, Vol. 10, No. 1, pp. 9-13, Feb. 2010.

[4] J.-H. Kim, Y.-C. Jung, S.-W. Lee, T.-W. Lee, and C.-Y. Won, "Power loss analysis of interleaved soft switching boost converter for single-phase pv-pcs," Journal of Power Electronics, Vol. 10, No. 4, pp. 335-341, Aug. 2010.

[5] I.-D. Kim, J.-Y. Kim, E.-C. Nho, and H.-G. Kim, "Analysis and design of a soft-switched pwm sepic dc-dc converter," Journal of Power Electronics, Vol. 10, No. 5, pp. 461-467, Oct. 2010.

[6] X. Xie, J. Zhang, Z. Chen, Z. Zhao, and Z. Qian, "Analysis and optimization of LLC resonant converter with a novel over-current protection circuit," IEEE Trans. Power Electron. Vol. 22, No. 2, pp. 435-443, Apr. 2007.

[7] D. Sha, Z. Guo, and X. Liao, "Digital control strategy for input-seriesoutput-parallel modular dc/dc converters," Journal of Power Electronics, Vol. 10, No. 3, pp. 245-250, Jun. 2010.

[8] B. R. Lin and J. J. Chen, "Analysis of an integrated flyback and zeta converter with active clamping technique," IET Proc. - Power Electron., Vol. 2, No. 4, pp. 355-363, 2009.

[9] S.-S. Hong, S.-K. Ji, Y.-J. Jung, and C.-W. Roh, “ Analysis and design of a high voltage flyback converter with resonant elements," Journal of Power Electronics, Vol. 10, No. 2, pp. 107-114, Apr. 2010.

[10] S. S. Lee, S. W. Choi, and G. W. Moon, "High-efficiency active-clamp forward converter with transient current build-up (TCB) ZVS technique," IEEE Trans. Ind. Electron., Vol. 54, No. 1, pp. 310-318, Feb. 2007.

[11] J. J. Lee, J. M. Kwon, E. H. Kim, and B. H. Kwon, "Dual series-resonant active-clamp converter," IEEE Trans. Ind. Electron., Vol. 55, No. 2, pp. 699-710, Feb. 2008.

[12] T. S. Kim, S. K. Han, G. W. Moon, and M. J. Youn, "High efficiency active clamp forward converter for sustaining power module of plasma display panel," IEEE Trans. Ind. Electron., Vol. 55, No. 4, pp. 1874 1876, Apr. 2008.
[13] B. R. Lin and H.K. Chiang, "Analysis and implementation of a soft switching interleaved forward converter with current doubler rectifier," IET Proc. - Electric Power Applications, Vol. 1, No. 5, pp. 697-704, Oct. 2007.

[14] W. Li and X. He, "ZVT interleaved boost converters for high-efficiency, high step-up DC-DC conversion," IET Proc. - Electric Power Applications, Vol. 1, No. 2, pp. 284-290, Apr.2007.

[15] R. Torrico-Bascop and I. Barbi, "A double ZVS-PWM active-clamping forward converter: analysis, design, and experimentation," IEEE Trans. Power Electron., Vol. 16, No. 6, pp. 745-751, Dec. 2001.

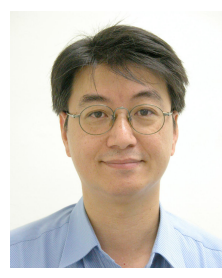

Bor-Ren Lin received his B.S. in Electronic Engineering from the National Taiwan University of Science and Technology, Taipei, Taiwan, in 1988, and his M.S. and Ph.D. in Electrical Engineering from the University of Missouri, USA, in 1990 and 1993, respectively. From 1991 to 1993, he was a Research Assistant with the Power Electronic Research Center, University of Missouri. Since 1993, he has been with the Department of Electrical Engineering, National Yunlin University of Science and Technology, Douliou, Taiwan, where he is currently a Professor. $\mathrm{He}$ has authored more than 300 published technical conference and journal papers in the area of power electronics. His main research interests include power-factor correction, multilevel converters, active power filters, and softswitching converters. Dr. Lin is an Associate Editor of the IEEE Transactions on Industrial Electronics and The Institution of Engineering and Technology Proceedings-Power Electronics. He was the recipient of Research Excellence Awards in 2004, 2005, and 2007 from the College of Engineering, National Yunlin University of Science and Technology. He received best paper awards from the IEEE Conference on Industrial Electronics and Applications 2007 and 2011, from the Taiwan Power Electronics 2007 Conference, and from the IEEE Power Electronics and Drive Systems 2009 Conference.

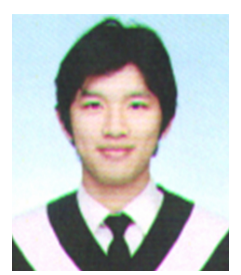

Li-An Lin is currently working toward his M.S. in Electrical Engineering from the National Yunlin University of Science and Technology, Yunlin, Taiwan. His research interests include the design and analysis of power factor correction techniques, switching mode power supplies and soft switching converters. 